\title{
AVALIAÇÃO DA RESISTÊNCIA FLEXURAL EM DIFERENTES MÉTODOS DE SOLDAGEM
}

\section{EVALUATION OF FLEXURAL RESISTANCE IN DIFFERENT WELDING METHODS}

\author{
Victor Padilha de Menezes* \\ Sergio Candido Dias* \\ Geraldo Alberto Pinheiro de Carvalho*** \\ Elimário Venturin Ramos**** \\ Aline Batista Gonçalves Franco \\ Simone Kreve ${ }^{*+* * * * *}$
}

\section{RESUMO}

\begin{abstract}
O objetivo do presente estudo foi avaliar três diferentes tipos de soldagem: Chama Direta a maçarico (convencional \brasagem), Solda Mista representada por fixação de dois pontos (Solda Elétrica Fixator - Kernit, Brasil), e completada com solda convencional, e o método de Solda a Laser (Soldadora Desktop - Sisma LM 500, Itália). Dois implantes plataforma Bränemark $4.1 \mathrm{~mm}$ (Neodent, Curitiba/Brasil) foram fixados em uma matriz de alumínio para simular uma ponte fixa implanto-suportada de três elementos. Os espécimes foram obtidos a partir de um bloco de cera CAD-CAM (Ceramill-Amammgirrbarch). Trinta e duas UCLAs hexágono externo foram fresadas e posteriormente unidas a uma barra pré-fabricada em cera com 2,5mm. Os corpos de prova foram fundidos em liga de cobalto-cromo simulando uma prótese fixa de três elementos. Esses espécimes foram divididos aleatoriamente e separados em três grupos $(n=6)$ : grupo A (solda chama direta), grupo B (solda mista), grupo C (solda laser). Os espécimes foram seccionados ao meio e unidos com resina acrílica para simular uma soldagem em prótese fixa. Os corpos foram soldados e tratados de acordo com a proposição. Após a soldagem os corpos de prova foram usinados e levados ao teste de flexão na técnica de três pontos. Os dados foram submetidos aos testes estatísticos de Tukey. Os cálculos estatísticos foram conduzidos adotando-se o nível de significância de $5 \%(\alpha=0,05)$. Houve diferença estatisticamente significativa entre os grupos soldados. Os resultados demonstraram valores mais elevados nos grupos A e B, solda convencional e solda mista, e menor valor no grupo C, solda a laser. No entanto, considerando a metodologia aplicada, a solda a laser mostrou uma menor resistência flexural comparada à soldagem convencional e mista, e a fixação prévia de solda elétrica com complemento de solda convencional (solda mista) não alterou a resistência flexural, produzindo resultado semelhante à solda convencional.
\end{abstract}

Descritores: Soldagem · Lasers · Implantes dentários · Soldagem em odontologia.

\section{ABSTRACT}

The objective of this study was to evaluate three different types of welding, blowtorch; (conventional/brazing), welder Joint; represented by securing two points (Arc Welding Fixator - Kernit, Brazil), and supplemented with conventional welding), and Laser welding method (welder Desktop - Sisma LM 500, Italy). Two implants Bränemark $4.1 \mathrm{~mm}$ platform (Neodent, Curitiba/Brazil) were fixed in an aluminum matrix. Specimens were obtained from a CAD-CAM wax block (Ceramill - Amammgirrbarch) were milled 32 UCLAs (external hexagon, Bränemark platform), and subsequently joined to a prefabricated bar also wax $2.5 \mathrm{~mm}$, the specimens were casted in cobalt-chromium alloy. These specimens were randomly divided and separated into 3 groups: group A (welding direct flame), Group B (mixed welding), C (laser welding), with 6 samples for each group. The specimens of each group were cut in half to simulate a fixed prosthesis in welding, and put together with acrylic resin. The bodies were welded and treated according to the statement. After the specimens were welded, they were manually grinded and submitted to the 3 points bending test technique. Data were subjected to statistical tests of Tukey. Statistical calculations were performed adopting the significance level of $5 \%(\alpha=0.05)$, using SPSS 20 (SPSS Inc., Chicago, IL, USA). There were differences between the soldered groups. The data showed the highest values obtained in groups $A$ and $B$, conventional welding and soldering joint, and lower in group $\mathrm{C}$, the laser welding. However, within the applied methodology, the laser welding showed a lower flexural strength compared to conventional and mixed welding, and that the advance fixing of electric welding, conventional welding complement (mixed welding), does not change its flexural strength, producing results similar to conventional welding.

Descriptors: Welding · Lasers · Dental implants · Dental Soldering.

\footnotetext{
* Mestre em prótese dentária pela Faculdade São Leopoldo Mandic/Campinas SP victorpvix@hotmail.com

** Doutor em reabilitação Oral pela USP-Ribeirão Preto/SP cdsergio@uol.com.br

*** Mestre em Clínica Odontológica pela Unicor-3 Corações/MG cdgeraldo@yahoo.com.br

**** Mestre em prótese dentária pela Faculdade São Leopoldo Mandic/Campinas SP drelimario@hotmail.com

***** Mestre em endodontia pela Faculdade São Leopoldo Mandic/Campinas SP alinebgf@uit.br

****** Mestre em prótese dentária pela Faculdade São Leopoldo Mandic/Campinas SP simonekreve@hotmail.com
} 
MENEZES VP

DIAS SC

CARVALHO GAP

RAMOS EV

FRANCO ABG :

KREVE $S$

AVALIAÇÃO DA

RES ISTENNCIA

FLEXURAL EM

DIFERENTES

MÉTODOS DE

SOLDAGEM

216

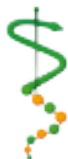

REV, ODONTOL.

UNIV, CID, SÃO

PAULO

2017; 29(3):

215-29, SET-DEZ

\section{INTRODUÇÃO}

O sucesso biomecânico de uma prótese dentária está diretamente relacionado com a passividade da sua infraestrutura metálica ${ }^{1,2}$. Durante a confecção de próteses fixas, convencionais ou sobre implantes, pode ser necessário um processo de soldagem. Quando a prótese não encaixa passivamente nos implantes, forças de compressão e torques são aplicados ao sistema osso-implante-prótese, o que pode causar fratura da peça protética ou mesmo do parafuso do implante ${ }^{3}$. A soldagem é um dos métodos para unir metais, seja para construção de superestruturas com múltiplos componentes ou para reparar próteses quebradas ${ }^{4}$, e pode ser realizada por diferentes métodos como: soldagem a arco, soldagem por resistência, soldagem a gás, soldagem a gás de arco de metal, soldagem a gás de arco de tungstênio, soldagem por arco submerso, soldagem por feixe de energia e soldagem por feixe de laser $^{2}$. As fundições de próteses fixas extensas de peça única são um procedimento sensível que apresenta certo grau de distorção ${ }^{5}$.

Quando a adaptação clínica da infraestrutura com o pilar intermediário do implante não é obtida inicialmente através de uma peça fundida em monobloco, o seccionamento e a soldagem são estratégias comuns para melhorar essa adaptação. A técnica de soldagem apresenta a vantagem de trabalhar com segmentos da prótese, os quais permite melhor adaptação, favorecendo, assim, a distribuição de forças ao redor do implante, minimizando traumas ou falhas na prótese ${ }^{6}$. Nesse âmbito, o uso de outros procedimentos de soldagem, como a solda por energia Laser, tem aumentado e tem sido indicado para uniões de infraestruturas na Odontologia ${ }^{4}$, $7,8,9$. A soldagem a laser demonstrou ser um método eficiente para obter uma meIhor adaptação de estruturas suportadas por implantes ${ }^{10}$. Algumas vantagens desse método são a ausência de contato direto com a área soldada, área de soldagem mais definida com menor aquecimento e nenhuma influência de campo magnético no feixe de laser ${ }^{11,12}$. Como a energia da soldagem a laser pode ser concentrada em uma área pequena, há menos efeitos de aquecimento e oxidação na área mais larga que rodeia a área a ser soldada ${ }^{4}$. Os espécimes soldados por processos a laser são menos susceptíveis à corrosão ${ }^{8}$.

Os fatores que afetam a resistência mecânica das juntas soldadas a laser são o comprimento de onda, a potência de pulso de pico, a energia do pulso, a energia de saída, a duração do pulso, a frequência de pulso, o diâmetro da ponta da máquina de solda a laser e o tipo de metal usado. ${ }^{4}$ A liga de cobalto-cromo ( $\mathrm{Co}-\mathrm{Cr}$ ) é a mais comumente utilizada para confecção das estruturas metálicas de próteses dentárias ${ }^{4}$. Os procedimentos mais comuns para juntar uma liga de cobalto-cromo (Co-Cr) são a solda ou brasagem ${ }^{4,13}$. Se o processo de junção for inferior a 425 C, a operação é chamada de solda. No entanto, se a temperatura estiver acima de 425 C, é chamada de brasagem ${ }^{13}$.

O titânio comercialmente puro (CP Ti) destaca-se com sucesso como material de implante e como estrutura metálica da prótese devido à biocompatibilidade e baixo custo ${ }^{7}$. No entanto, a forte reatividade química do Ti e seu rápido nível de reação e difusão em altas temperaturas resultam em problemas com processos de soldagem, fusão e brasagem ${ }^{8}$. Para assegurar uma melhor adaptação final da peça protética recomenda-se a utilização de componentes pré-fabricados. Entre os disponíveis no mercado encontram-se os cilindros de titânio, os cilindros de ouro e os de cobalto-cromo. Como todas as restaurações protéticas são submetidas a estresses térmicos, químicos ou mecânicos, além de estarem em contato direto com os fluidos bucais, a escolha de um material de má qualidade pode resultar em uma prótese com problemas de adaptação e o resultado estará diretamente relacionado à sua longevidade.

O objetivo deste trabalho foi avaliar a resistência flexural entre três métodos de soldagem: chama direta; solda mista composta por fixação de Eletro-Solda associada a chama direta; e a solda laser.

\section{MATERIAIS E MÉTODOS}

Os materiais utilizados estão demonstrados no Quadro 1. 


\begin{tabular}{lll}
\hline \hline MATERIAL & MARCA & MODELO \\
\hline LIGA METÁLICA & DENTSPLY & CO-CR DEGUDENT \\
REVESTIMENTO FUNDIÇÃO & YETI & EXPANSION \\
REVESTIMENTO SOLDAGEM & POLIDENTAL & HI FUSION \\
LIGA DE SOLDA & TALADIUM & CR-CO FLEX \\
SPRUE PARA INCLUSÃO & ACÁCIA & SPEED SPRUE \\
REDUTOR TENSÃO SUPERFICIAL & POLIDENTAL & SURFACER \\
RESINA ACRÍLICA & GC & PATTERN RESIN \\
FLUXO & ALBADENT & VERA FLUX \\
\hline \hline
\end{tabular}

Fonte: Autoria própria.

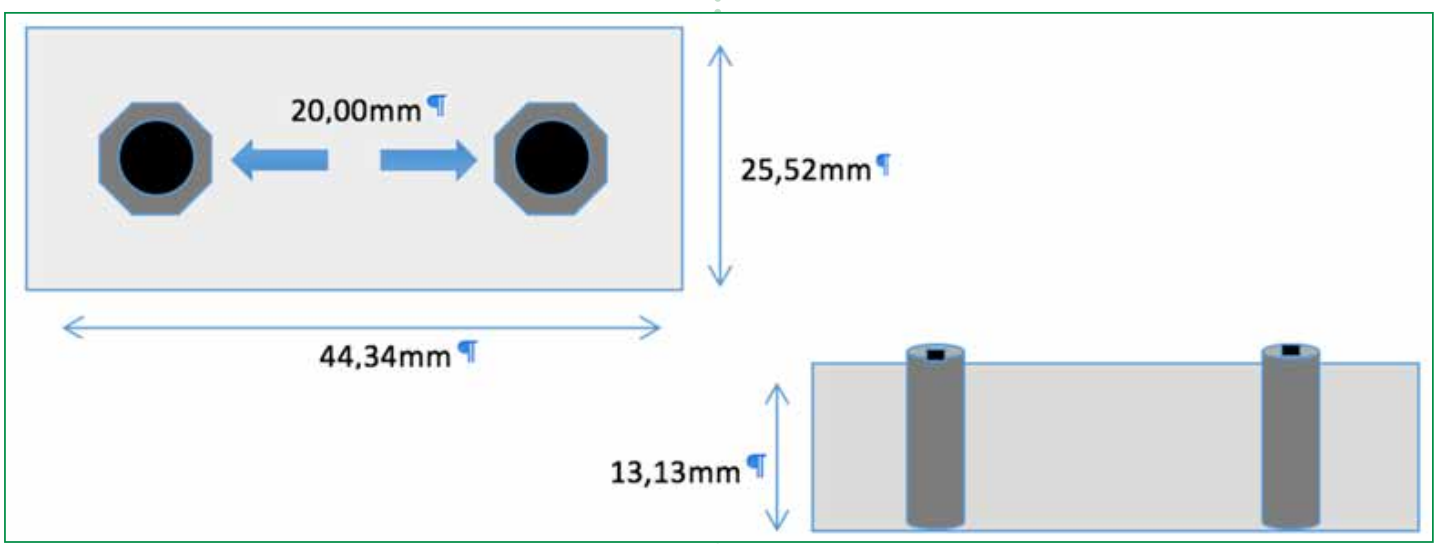

Figura 1- Desenho esquemático do modelo-mestre.

Para confecção do modelo-mestre, foi utilizado um bloco de alumínio de $44,34 \mathrm{~mm}$ de comprimento, 25,52mm de largura e $13,13 \mathrm{~mm}$ de altura. Foram realizadas duas perfurações paralelas entre si e perpendiculares à superfície do bloco de alumínio com o auxílio de uma fresadora. Os orifícios foram dispostos à distância de 20mm entre si e centralizados sobre o bloco. Em seguida, foi utilizada a broca formadora de rosca de diâmetro de $3,6 \mathrm{~mm}$, com o intuito de permitir o aparafusamento de dois implantes no bloco de alumínio proporcionando fixação adequada (Figura 1).

Após finalizada a construção do modelo-mestre, dois implantes Neodent (Curitiba/PR - Brasil, REF. 109.302), com tamanho de $3,75 \times 11 \mathrm{~mm}$, e plataforma de $4.1 \mathrm{~mm}$ foram instalados com o auxílio de um torquímetro mecânico com estabilidade de $50 \mathrm{~N}$ (Catraca Torquímetro Protética, cód. 104.026, Neodent, Brasil).

\section{Confecção dos corpos de prova}

Para a confecção dos corpos de prova, um Jig de referência foi aparafusado aos implantes então fixados na barra de alumínio, e foi levado ao scanner (Ceramill Map 300 - Amanngirrbach) para reprodução virtual da barra e da posição dos implantes. Foi confeccionado um projeto virtual contendo 2 UCLAs adaptadas aos implantes fixados na barra do modelo-mestre. Finalizado o projeto pelo software (Ceramil Mind - Amanngirrbach), um bloco de cera foi utilizado para fresagem CAD-CAM. Finalizado o processo de fresagem, o bloco de cera foi removido e os componentes em cera foram assentados sobre os implantes utilizando parafusos hexagonais de titânio (Neodent). Bastões de cera (Ceras Babinete Ltda., Brasil) pré-fabricados com $2,5 \mathrm{~mm}$ de diâmetro foram recortados e unidos à porção dos dois pilares UCLA e posicionados $4 \mathrm{~mm}$ acima da plataforma do implante em todas as estruturas. Um gabarito de silicone foi confeccionado para padronização dos espécimes de cera. Foram confeccionados 18 corpos de prova, utilizando-se 32 pilares UCLAs.
CARVALHO GAP

Ramos eV

FRANCO ABG

KREVES

AVALIAÇÃO DA RES ISTENNCIA FLEXURAL EM DIFERENTES MÉTODOS DE SOLDAGEM

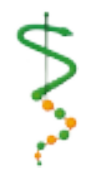


MENEZES VP

DIAS SC

CARVALHO GAP

RAMOS EV

FRANCO ABG

KREVE S

AVALIAÇÃO DA RES ISTENNCIA

FLEXURAL EM DIFERENTES MÉTODOS DE SOLDAGEM

\section{8}

REV, ODONTOL.

UNIV, CID. SÃO

PAULO

2017; 29(3):

$215-29, S$ ET - DEZ

\section{Inclusão}

Cada anel de inclusão recebeu três espécimes, que foram posicionados em uma barra pré-fabricada em cera com espessura de $5 \mathrm{~mm}$ no centro térmico de um anel de silicone com capacidade para $120 \mathrm{~g}$ de revestimento. Foi verificado se a altura do enceramento em relação à borda do anel de fundição estava a cerca de $5 \mathrm{~mm}$ aquém da borda, para evitar a proximidade do enceramento com a borda mais externa do revestimento de fundição. Aplicou-se um agente redutor de tensão superficial (Anti-bolhas- Surfacer, Polidental - São Paulo/ SP) em toda a superfície dos padrões de cera, tendo sido os excessos removidos com jatos de ar bem brando, evitando, assim, qualquer movimentação dos padrões fixados ao sprue.

Em seguida, um revestimento do tipo aglutinado por fosfato de micropartículas foi aplicado sobre os corpos de prova e, em seguida, o anel de silicone foi preenchido por completo com o revestimento, por meio da técnica manual e com auxílio de vibração mecânica.

\section{Fundição}

Após o tempo de presa do revestimento (25 minutos, a uma temperatura de $23^{\circ} \mathrm{C}$ ), foi realizada a remoção da base formadora de cadinho, do anel de silicone, e dos resíduos da porção mais externa, em cerca de $2,5 \mathrm{~mm}$, para que a mesma não impedisse a eliminação dos gases do revestimento durante a fundição. $\mathrm{O}$ conjunto obtido na inclusão foi levado ao forno a uma temperatura de $870^{\circ} \mathrm{C}$ por 45 minutos para eliminação da cera. $\mathrm{O}$ cadinho cerâmico (quartzo), previamente aquecido, foi posicionado no braço da centrífuga para fundição. Uma liga de Co-Cr (Co-Cr DeguDent, Dentsply, Brasil) foi colocada no centro do cadinho e fundida de forma uniforme e gradual, com o uso de um maçarico com adequadas proporções de propano/oxigênio. A obtenção do aspecto visual da liga em sua faixa de fusão $\left(1.320^{\circ} \mathrm{C}\right.$ a $\left.1.380^{\circ} \mathrm{C}\right)$ determinou $\mathrm{o}$ momento de liberar a trava da centrífuga, para que o metal fosse injetado no interior do anel de fundição.

\section{Desinclusão}

Após o resfriamento natural do anel, aproximadamente 2 horas em temperatura ambiente $\left(22^{\circ} \mathrm{C}\right)$, foram realizadas as desinclusões com suaves cortes laterais do anel de revestimento e aplicação de jato de óxido de alumínio com granulatura de $125 \mathrm{~m}$ sob pressão $5,08 \mathrm{Kg} / \mathrm{cm} 2$. Os condutos de alimentação foram seccionados e as superfícies internas dos cilindros avaliadas com o cuidado de detectar qualquer tipo de impureza ou microbolhas.

As fases laboratoriais de enceramento

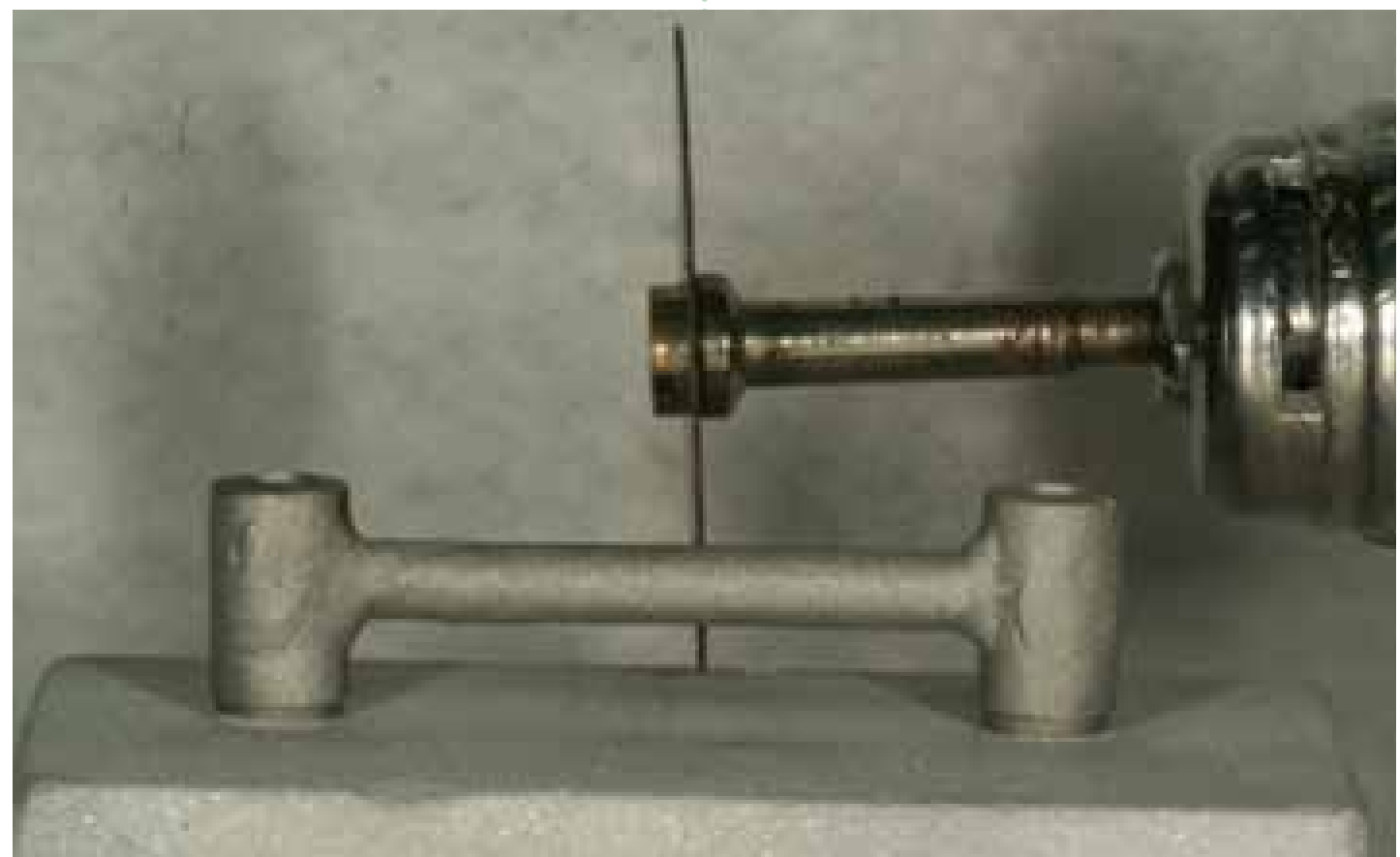

Figura 2 - Corpo de prova sendo seccionado para preparo de soldagem. 
e fundição das estruturas foram realizadas por um único operador.

Preparo da área de soldagem

As estruturas metálicas foram posicionadas sobre o modelo-mestre e marcadas com ponta esférica diamantada $n^{0} 1 / 2$, no centro das faces vestibulares dos implantes e na região correspondente de cada pilar da estrutura com o intuito de determinar a referência de posicionamento. Marcações também foram executadas nas faces distais e linguais onde as medidas das interfaces pilar/implante foram realizadas. Todos os corpos de prova foram jateados previamente à soldagem para garantir a sua limpeza.

Distribuição dos grupos

Os corpos de prova foram numerados aleatoriamente de 1 a 18 e divididos em 3 grupos:

a) Grupo A: composto por 6 infraestruturas soldadas pela técnica convencional - chama direta ( $n^{\circ} 1$ a 6 );

b) Grupo B: composto por 6 infraestruturas soldadas pela técnica de soldagem mista ( $n^{\circ} 07$ a 12);

c) Grupo C: composto por 6 infraestruturas soldadas pela técnica a laser
( $\mathrm{n}^{\mathrm{o}} 13$ a 18).

\section{Soldagem convencional}

As superfícies dos corpos de prova receberam acabamento com pedra de óxido de alumínio. Para a união dos segmentos, foi utilizada pequena quantidade de resina acrílica autopolimerizável com auxílio de pincel. Após 5 minutos foi acrescentada mais uma camada da mesma resina para reforço. Os parafusos foram soltos somente 15 minutos após a última camada. A quantidade de resina acrílica foi padronizada em $0,2 \mathrm{~g}$ de polímero para três gotas de monômero para cada ponto de união. Os segmentos unidos com resina acrílica foram posicionados em uma mesma base de silicone, com o intuito de padronizar a quantidade de revestimento que recobriria as infraestruturas, e incluídos sempre com a mesma quantidade de revestimento. Após 2 horas, à temperatura ambiente (aproximadamente $23^{\circ} \mathrm{C}$ ), o revestimento contendo a infraestrutura foi levado ao forno de fundição, para ser desidratado.

O conjunto corpos de prova/revestimento foi removido do forno e a soldagem foi executada com maçarico gás/ oxigênio de cone único, com a chama
MENEZES VP

DIAS SC

CARVALHO GAP

Ramos eV

FRANCO ABG

KREVES

AVALIAÇÃO DA

RESISTENNCIA

FLEXURAL EM

DIFERENTES

MÉTODOS DE

SOLDAGEM

Fonte: Autoria própria.

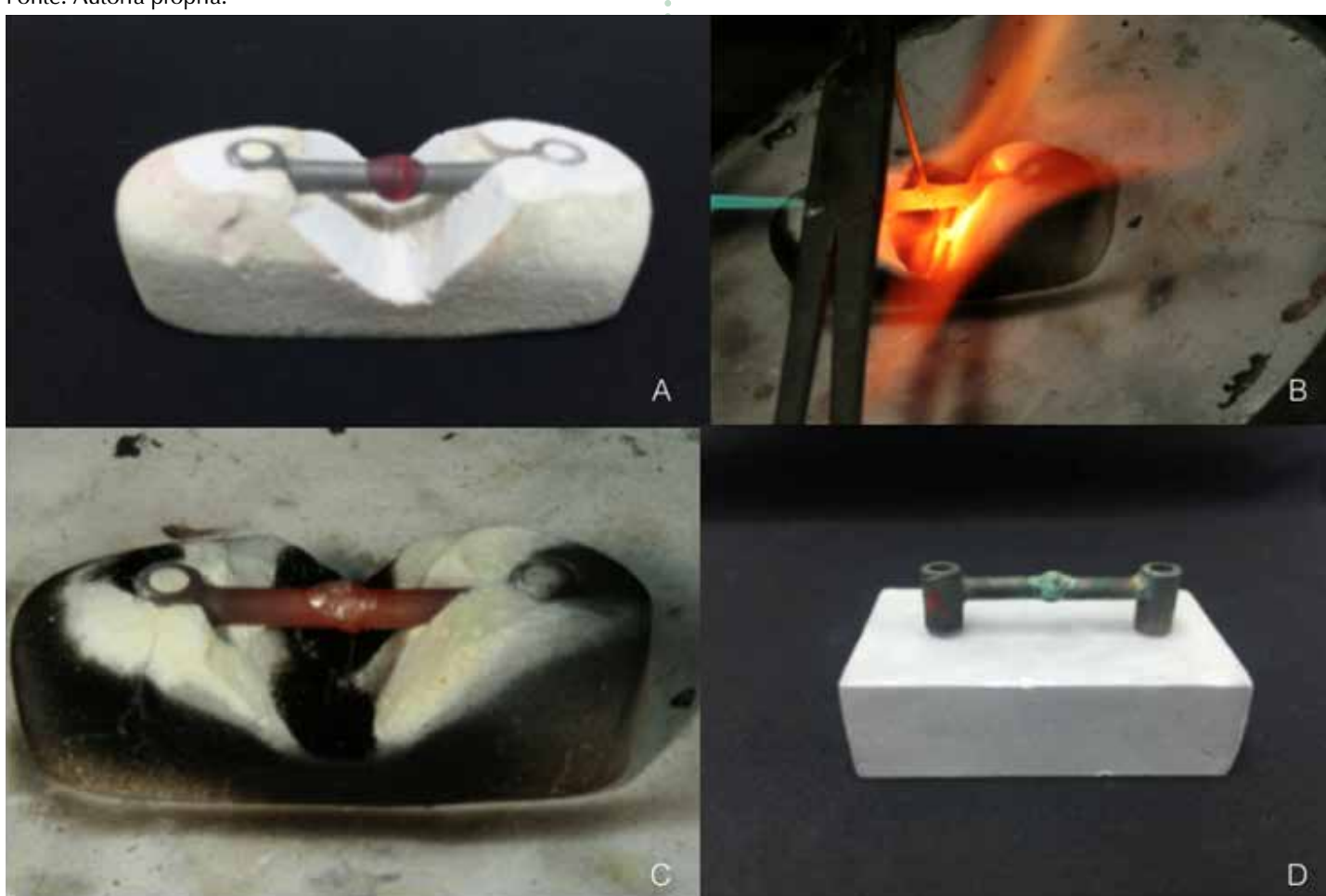

Figura 3 - Soldagem convencional. A) Corpo de prova incluído pronto para soldagem; B) momento exato da soldagem a maçarico; C) Aspecto logo após soldagem; D) Corpo de prova fixado ao modelo-mestre após desinclusão. 
MENEZES VP

DIAS SC

CARVALHO GAP

RAMOS EV

FRANCO ABG

KREVE S

AVALIAÇÃO DA RES ISTENNCIA

FLEXURAL EM DIFERENTES MÉTODOS DE

SOLDAGEM redutora apresentando $3 \mathrm{~cm}$ de comprimento. Inicialmente, a chama com $45^{\circ}$ de inclinação foi aplicada sobre o espaço a ser soldado até que essa área apresentasse coloração vermelha. Foi utilizada solda para ligas à base de níquel, cromo e cobalto (Solda CrCo Flex - Taladium, Brasil), com faixa de fusão de $1.120^{\circ} \mathrm{C} / 1.150^{\circ} \mathrm{C}$ e fluxo para alta fusão (Vera flux, Albadent, EUA). Tomou-se o cuidado para que não houvesse interrupção do aquecimento até que a solda escoasse pela fenda. Imediatamente após o escoamento da solda, a chama foi removida. As infraestruturas com o revestimento foram deixadas à temperatura ambiente $\left(22^{\circ} \mathrm{C}\right)$ para resfriamento. A desinclusão foi realizada com jato de óxido de alumínio de granulação $125 \mathrm{~m}$ sob pressão $5,08 \mathrm{Kg} / \mathrm{cm} 2$. Os segmentos da infraestrutura foram completamente limpos com vapor de água antes de serem fixados com os parafusos na plataforma do modelo-mestre.

Soldagem mista (Eletro-solda e chama direta)

O processo de soldagem foi realizado no próprio modelo, pois durante a execução da mesma não há aquecimento perceptível na peça sendo que o calor de mais de $1.200^{\circ} \mathrm{C}$ é dissipado instantaneamente. Posteriormente à fixação de dois pontos de solda, a peça foi jateada com óxido de alumínio de granulação $125 \mathrm{~m}$ sob pressão $5,08 \mathrm{Kg} / \mathrm{cm} 2$ para limpeza da região a ser soldada. Pelo fato da peça estar fixada e estabilizada por dois pontos de solda a infraestrutura não passou pelo processo de inclusão. Removida do modelo-mestre a infraestrutura foi posicionada em uma base refratária e soldada conforme descrito na soldagem convencional. Tomou-se o cuidado para que não houvesse interrupção do aquecimento da região, ou que a chama causasse qualquer tipo de deformação, até que a solda escoasse pela fenda. Imediatamente após o escoamento da solda, a chama foi removida. A infraestrutura foi deixada à temperatura ambiente ( $23^{\circ} \mathrm{C}$ ) para resfriamento.

\section{Soldagem a laser}

Os espécimes foram posicionados ao modelo-mestre com parafuso com torque de $10 \mathrm{~N}$, e o processo de soldagem foi confeccionado no próprio modelo-mestre. A soldagem a laser foi realizada com máquina gerador Laser $\mathrm{Nd}$ :YAG (Neodímio-Yag) para execução de soldaduras manual (Laser LM 500, Sisma, Schio - Itá-

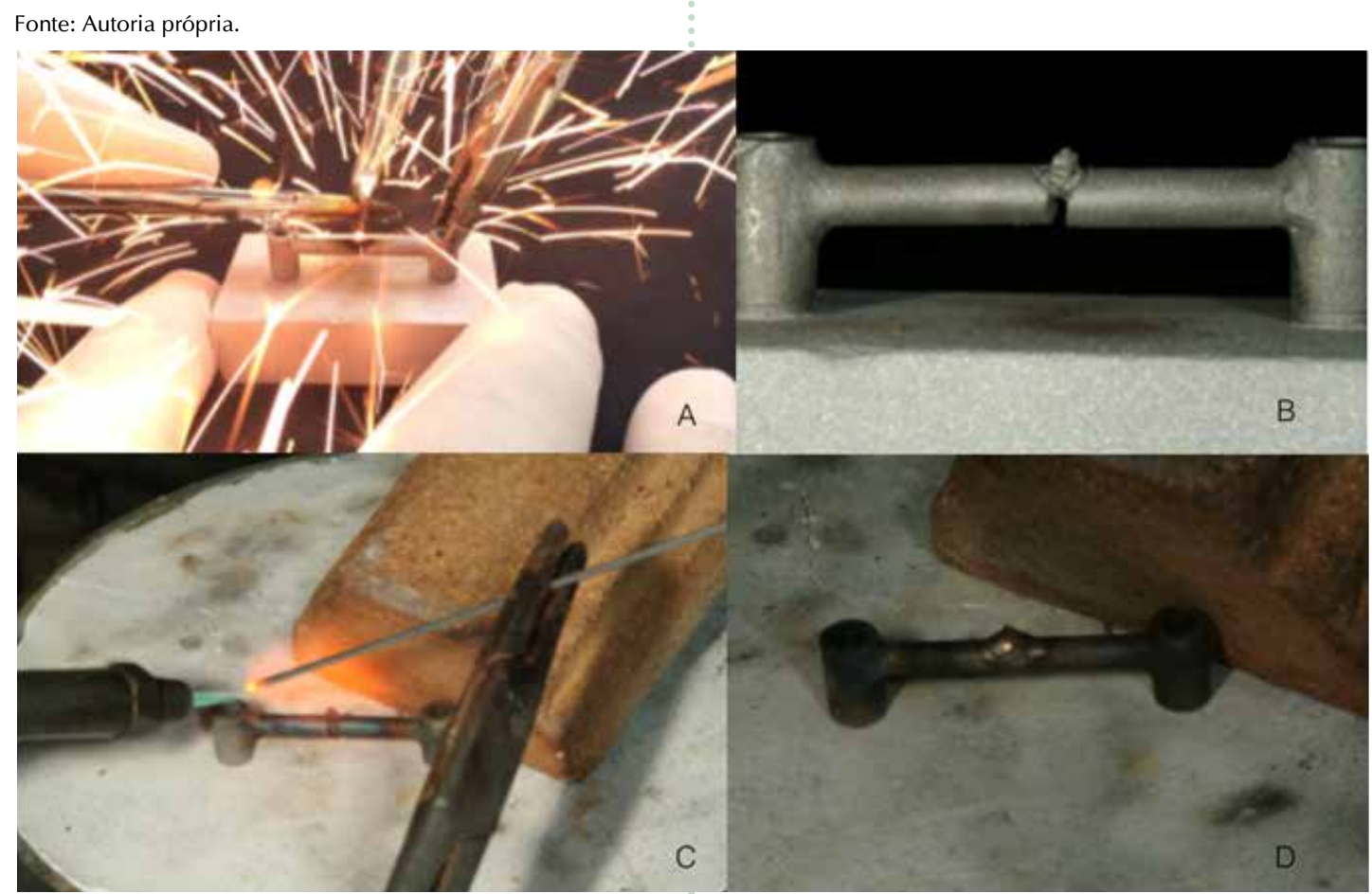

REV, ODONTOL.

Figura 4 - Soldagem mista. A) Soldagem de fixação; B) Corpo de prova no modelo mestre após jateamento; C) Completando com soldagem convencional; D) Aspecto da peça após soldagem. 
Figura 5

Soldagem a laser. A) Máquina de soldagem a laser Sisma LM 500;

B) visor de comando da soldadora indicando todos os valores empregados nesta soldagem; $C$ ) Momento da soldagem laser do corpo de prova; D) Aspecto do corpo de prova soldado e fixado ao modelo-mestre.

Fonte: Autoria própria.
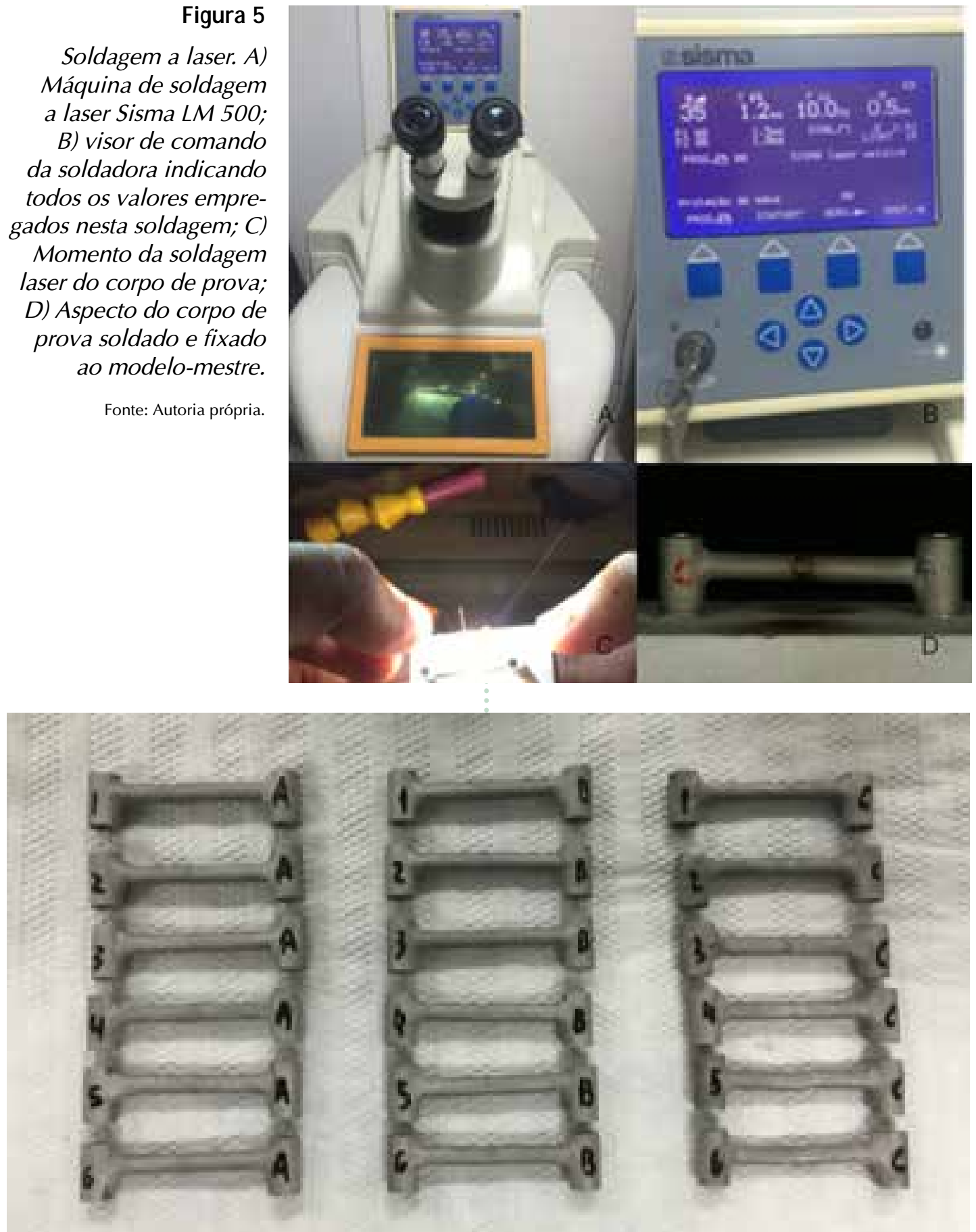

Figura 6 - Teste de resistência flexural

lia), com programação para disparos de potência de 35,0KW, duração do impulso de $1,2 \mathrm{~ms}$, frequência de $10 \mathrm{~Hz}$ e diâmetro do feixe de $0,5 \mathrm{~mm}$. Essa programação permitiu que o feixe do laser atingisse o centro da infraestrutura metálica.

Teste de Resistência Flexural

A resistência à flexão, também chamada de resistência transversa ou tensão de ruptura é, em análise geral, uma medida coletiva de todos os tipos de tensões agindo simultaneamente sobre um corpo ${ }^{14}$. Os ensaios de resistência à flexão foram reali- zados através da técnica dos 3 pontos com uma célula de carga de 200 kgf, regulada a uma velocidade de $2,0 \mathrm{~mm} / \mathrm{min}$. A transferência da força foi executada por intermédio de uma ponta de aço de $2,0 \mathrm{~cm}$ de diâmetro que contatava a região soldada, apoios. As infraestruturas foram medidas e marcadas com uma caneta esferográfica para que fosse padronizado o local a ser executado o teste de flexão. A cada grupo testado os parafusos de fixação foram substituídos por parafusos novos. posicionada no centro do espaço entre os
MENEZES VP

DIAS SC

CARVALHO GAP

RAMOS EV

FRANCO ABG

KREVES

AVALIAÇÃO DA

RES I STÊNCIA

FLEXURAL EM

DIFERENTES

MÉTODOS DE

SOLDAGEM 
MENEZES VP

DIAS SC

CARVALHO GAP

RAMOS EV

FRANCO ABG

KREVE $S$

AVALIAÇÃO DA

RES ISTENNCIA

FLEXURAL EM

DIFERENTES

METODOS DE

SOLDAGEM

222

\section{ANÁLISE ESTATÍSTICA}

Previamente às análises, os dados de resistência flexural foram avaliados quanto ao atendimento dos pressupostos de normalidade (teste de Shapiro-Wilk) e de homogeneidade de variância (teste de Levene) e submetidos à análise de variância a um critério. As comparações múltiplas foram efetuadas pelo teste de Tukey. Os cálculos estatísticos foram conduzidos adotando-se o nível de significância de $5 \%(\alpha=0,05)$, no programa SPSS 20 (SPSS Inc., Chicago, IL, EUA).

\section{RESULTADOS}

Os três grupos tiveram seus dados re-

Tabela 1 - Grupo A.

\begin{tabular}{lll}
\hline \hline Corpo de Prova & $\begin{array}{l}\text { Força } \\
\text { @Força Max. }\end{array}$ & $\begin{array}{l}\text { Força } \\
\text { @Força Max. } \\
\end{array}$ \\
\hline CP 1 & $(\mathrm{kgf})$ \\
CP 2 & 665,31 & 67,84 \\
CP 3 & 641,36 & 65,40 \\
CP 4 & 369,16 & 37,64 \\
CP 5 & 697,73 & 71,15 \\
CP 6 & 546,53 & 55,73 \\
Número CPs & 433,64 & 44,22 \\
Média & 6 & 6 \\
Mediana & 559,0 & 57,00 \\
Desv.-Padrão & 593,9 & 60,57 \\
Coef. Var.(\%) & 133,6 & 13,62 \\
\hline \hline
\end{tabular}

Fonte: Autoria própria.

Gráfico 1 - Valores obtidos no teste de resistência flexural do grupo A.

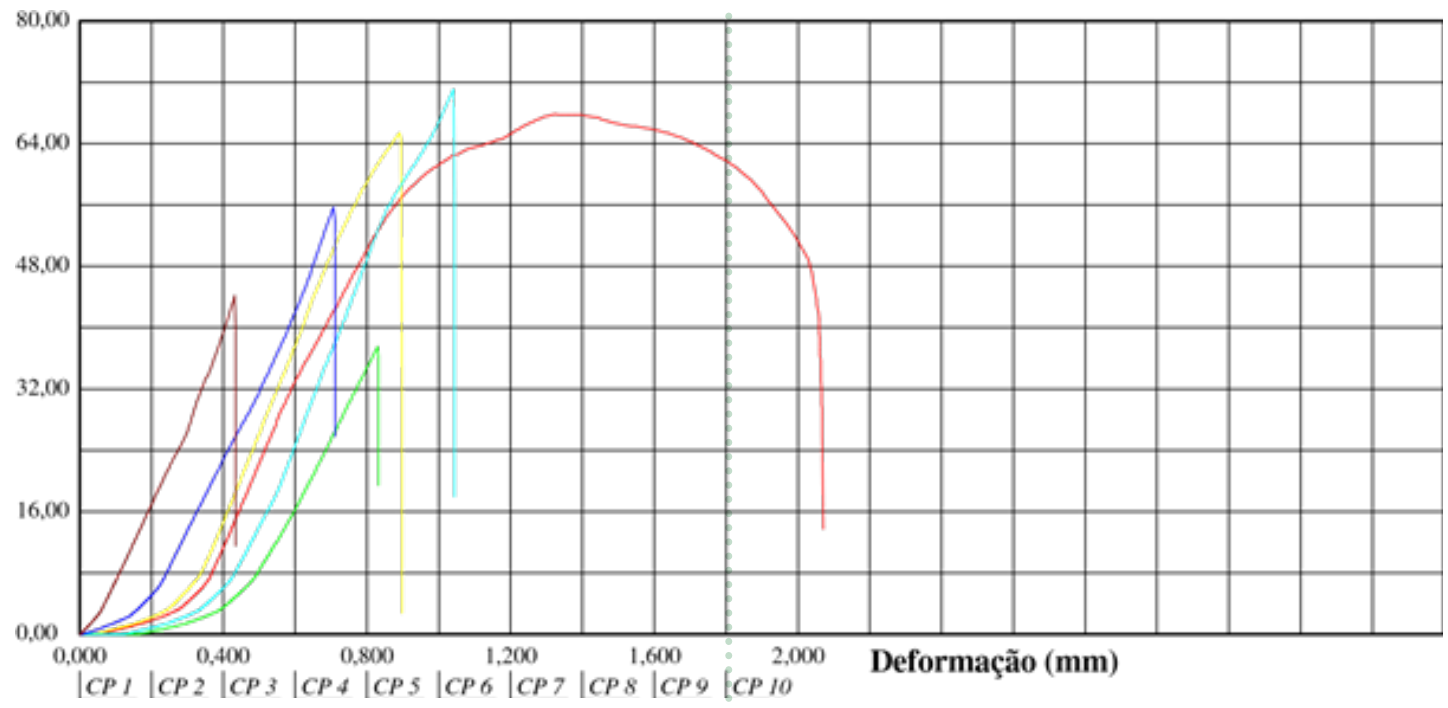

gistrados em $\mathrm{N}$ (newton) e KgF conforme as tabelas 1,2 e 3 .

A Tabela 4 sintetiza os valores médios e do desvio padrão da resistência flexural das infraestruturas fundidas em $\mathrm{Co}-\mathrm{Cr}$ e submetidas às técnicas convencional, mista e à laser de soldagem.

A análise de variância a um critério demonstrou que a resistência flexural das infraestruturas foi significativamente influenciada pela técnica de soldagem $(p=$ 0,011, com poder de teste de 81,9\%). Pelo teste de Tukey depreendeu-se que valores significativamente mais elevados de resistência foram obtidos com o emprego das técnicas convencional e mista, as quais
REV, ODONTOL.

UNIV, CID, SÃO PAULO

2017; 29(3): $215-29$, SET - DEZ

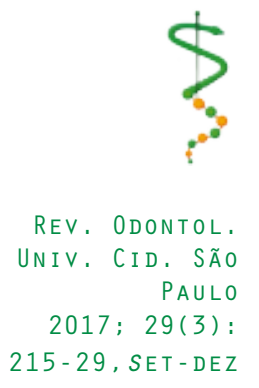


Tabela 2 - Grupo B

\begin{tabular}{lll}
\hline \hline $\begin{array}{l}\text { Corpo de Prova } \\
(\mathrm{N})\end{array}$ & $\begin{array}{l}\text { Força } \\
\text { @Força Max. } \\
(\text { kgf })\end{array}$ & $\begin{array}{l}\text { Força } \\
\text { @Força Max. }\end{array}$ \\
\hline CP 1 & 349,19 & 35,61 \\
CP 2 & 524,99 & 53,53 \\
CP 3 & 624,23 & 63,65 \\
CP 4 & 565,36 & 57,65 \\
CP 5 & 636,38 & 64,89 \\
CP 6 & 553,28 & 56,42 \\
Número CPs & 6 & 6 \\
Média & 542,2 & 55,29 \\
Mediana & 559,3 & 57,04 \\
Desv.Padrão & 103,7 & 10,58 \\
Coef.Var.(\%) & 19,13 & 19,13 \\
\hline \hline
\end{tabular}

Gráfico 2 - Valores obtidos no teste de resistência flexural do grupo B. Força (kgf) 80,00

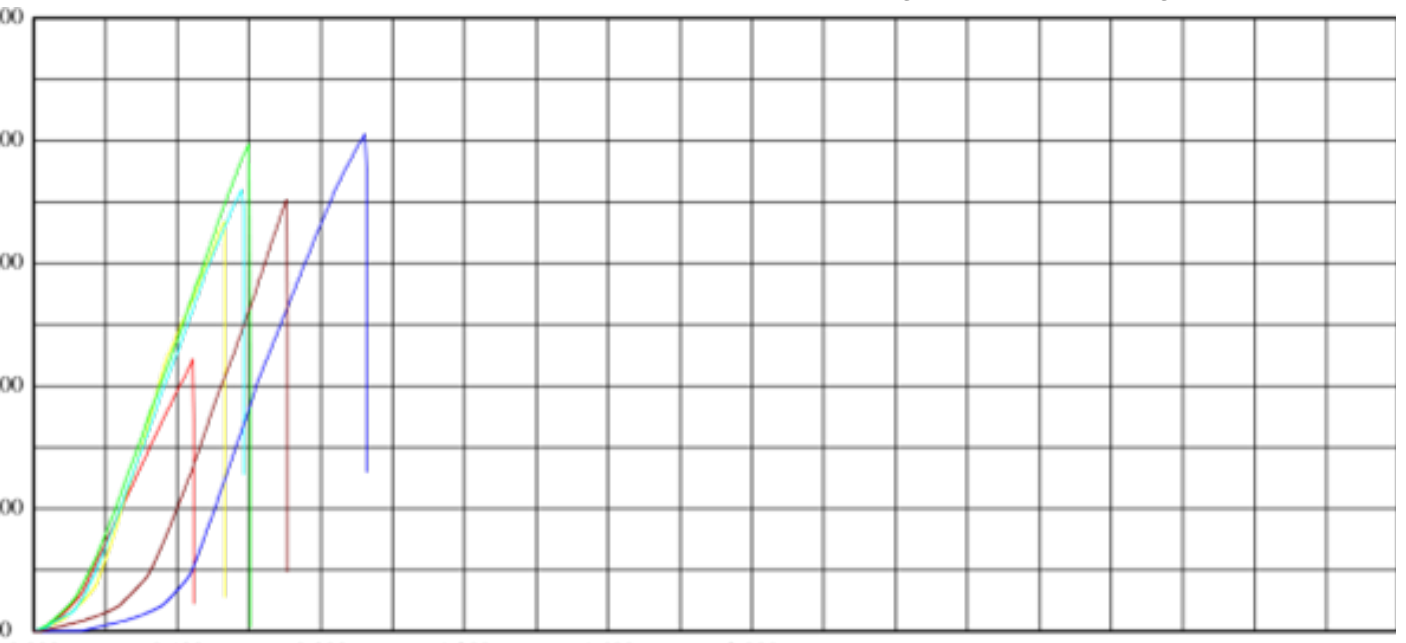

0,000

ICPI ICP2 |CP3 |CP4 ICP5 |CP6 |CP7 |CP\& |CP9 |CP 10

Fonte: Autoria própria.

Tabela 3 - Grupo C

\begin{tabular}{lll}
\hline \hline Corpo de Prova & $\begin{array}{l}\text { Força } \\
\text { @Força Max. } \\
(\mathrm{N})\end{array}$ & $\begin{array}{l}\text { Força } \\
\text { @Força Max. } \\
(\text { kgf })\end{array}$ \\
\hline CP 1 & 381,81 & 38,93 \\
CP 2 & 334,61 & 34,12 \\
CP 3 & 422,26 & 43,06 \\
CP 4 & 296,08 & 30,19 \\
CP 5 & 416,29 & 42,45 \\
CP 6 & 382,10 & 38,96 \\
Número CPs & 6 & 6 \\
Média & 372,2 & 37,95 \\
Mediana & 382,0 & 38,95 \\
Desv.-Padrão & 48,68 & 4,964 \\
Coef. Var.(\%) & 13,08 & 13,08 \\
\hline \hline
\end{tabular}

MENEZES VP

DIAS SC

CARVALHO GAP

RAMOS EV

FRANCO ABG

KREVES

AVALIAÇÃO DA

RESISTENNCIA

FLEXURAL EM

DIFERENTES

MÉTODOS DE

SOLDAGEM

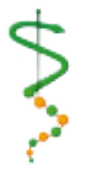

REV, ODONTOL.

UNIV. CID. SÃO

PAULO

2017; 29(3): 
MENEZES VP

DIAS SC

CARVALHO GAP

RAMOS EV

FRANCO ABG

KREVE S

AVALIAÇÃO DA

RES ISTENNCIA

FLEXURAL EM

DIFERENTES

METODOS DE

SOLDAGEM

Gráfico 3 - Valores obtidos no teste de resistência flexural do grupo C. Força (kgf)

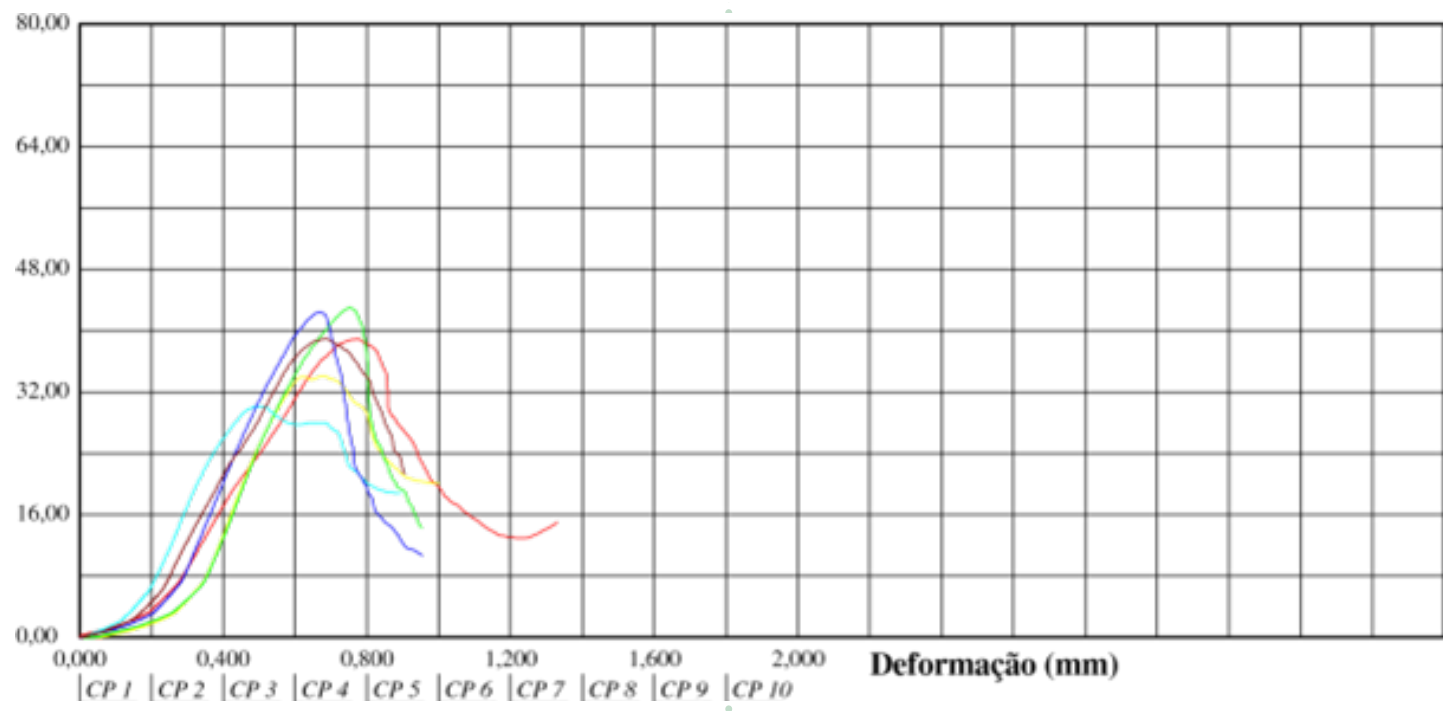

Fonte: Autoria própria.

Tabela 4 - Médias e desvio-padrão dos valores de resistência flexural de infraestruturas em $\mathrm{Co}-\mathrm{Cr}$, em função da técnica de soldagem.

\begin{tabular}{lll}
\hline $\begin{array}{l}\text { Técnica de } \\
\text { soldagem }\end{array}$ & N & $\begin{array}{l}\text { Resistência flexu- } \\
\text { ral }(\mathrm{MPa})\end{array}$ \\
\hline Convencional & 6 & $\begin{array}{l}1073,19(256,51) \\
\mathrm{A}\end{array}$ \\
Mista & 6 & $\begin{array}{l}1041,10(199,18) \\
\mathrm{A}\end{array}$ \\
A laser & 6 & \begin{tabular}{l}
$714,61(93,46) \mathrm{B}$ \\
\hline
\end{tabular}
\end{tabular}

Médias seguidas por letras distintas indicam diferença significativa entre as técnicas de soldagem. Fonte: Autoria própria. não apresentaram diferença significativa entre si (Tabela 1 e Gráfico 4). Já a soldagem a laser proporcionou à infraestrutura de Co-Cr os menores valores de resistência flexural. Especificamente, em relação às técnicas convencional e mista, ao se utilizar o laser, houve redução de 33,4\% e $31,4 \%$, respectivamente, na resistência flexural das infraestruturas.

Valores médios e respectivos desvios-padrão para a resistência flexural, de acordo com os grupos testados. Barras verticais indicam o desvio-padrão.

Gráfico 4 - Diagrama de colunas dos valores de resistência flexural de infraestruturas em Co-Cr, em função da técnica de soldagem.

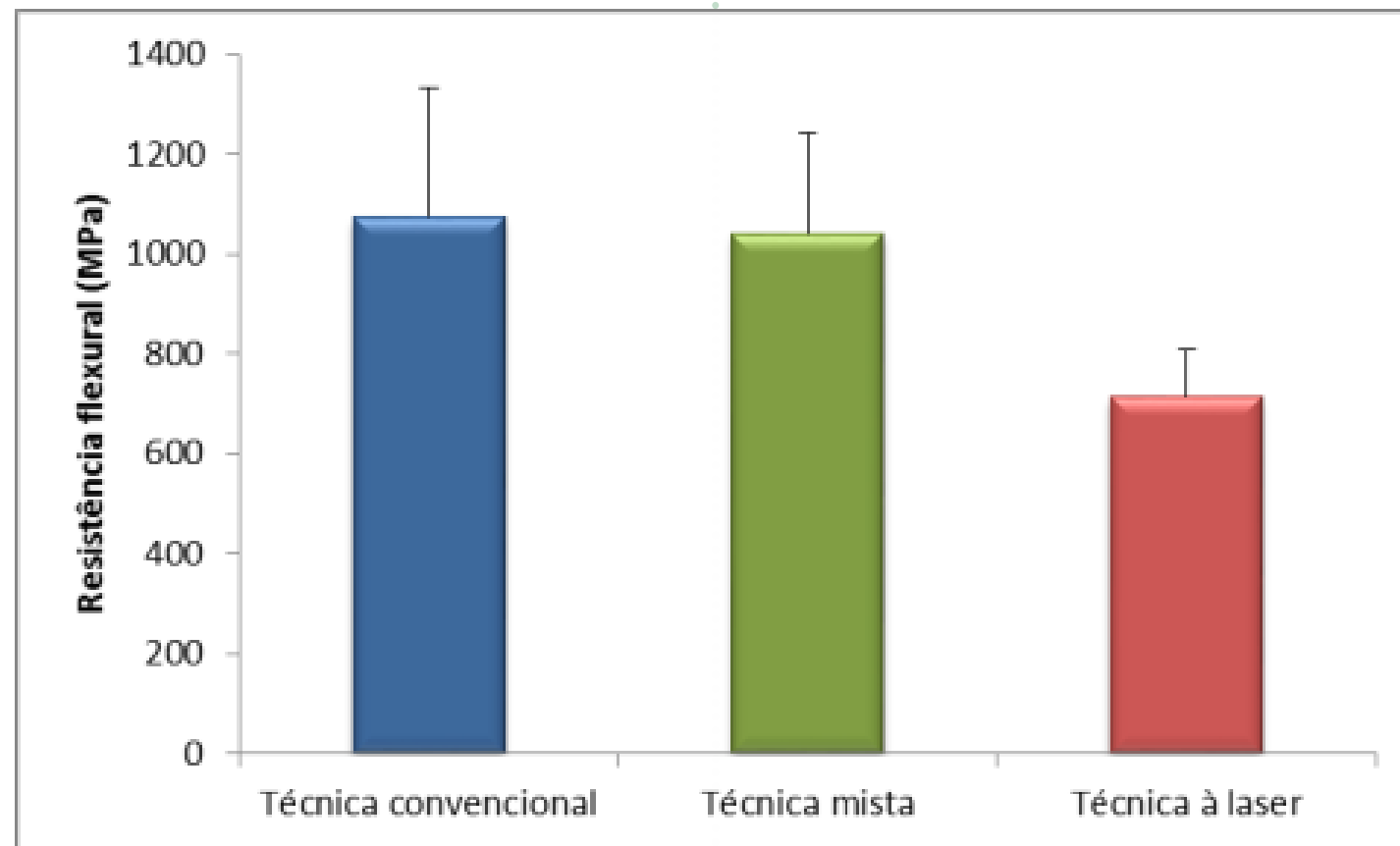

Fonte: Autoria própria. 


\section{I SCUSSÃO}

As reabilitações dentárias mediante próteses implanto-suportadas tornaram-se uma modalidade de tratamento bem consolidada na Odontologia devido às suas vantagens e, principalmente, ao seu elevado grau de sucesso. A passividade é obtida quando existe uma adaptação precisa entre os componentes protéticos e os implantes, sem formação de folga marginal ${ }^{10}$. Tal ajuste tem sido considerado um pré-requisito para a osseointegração ${ }^{15}$, e intensamente discutido na literatura ${ }^{6,10,16}$.

A soldagem em odontologia se tornou um processo rotineiro e comum, como solução para o perfeito assentamento e adaptação de peças protéticas, especialmente as mais extensas ${ }^{14,17}$. Para que determinada restauração protética adquira sucesso a longo prazo devem ser considerados: ausência de fratura, fatores como módulo de elasticidade da liga, espessura da estrutura da liga, o material da liga utilizada, presença ou ausência de bruxismo e outros hábitos orais, defeitos estruturais como porosidades decorrentes da fundição e ajuste impróprio. ${ }^{2}$ Todavia, a soldagem não está isenta de falhas ou defeitos, sejam de natureza técnica/processual ou humana, podendo comprometer significativamente a resistência flexural da solda e dos componentes ${ }^{5}$.

As estruturas para próteses implanto-suportadas podem ser constituídas de peças extensas. A fundição de uma peça única incorporando peças pré-fabricadas com superfícies usinadas capazes de propiciar encaixe preciso e passivo à superestrutura do implante se tornou um procedimento ainda mais difícil. Como resultado, o dentista deve ter um método eficaz de compensar as peças fundidas mal ajustadas ${ }^{18}$. Na solda dentária convencional, os metais originais são unidos a outros tipos de metais, o que pode reduzir a resistência à corrosão devido à corrosão galvânica entre os metais. ${ }^{4}$ Angelini et al. ${ }^{19}$ (1991) relataram diminuição da a resistência à tração da liga de Co-Cr soldada com base em ouro devido à corrosão galvânica. Vários autores discutiram a desadaptação marginal das infraestruturas e avaliaram as fundições de infraestruturas em monobloco, comprovando o seu elevado índice de desadaptação ${ }^{5,20,21}$.

O Co-Cr é uma liga metálica não nobre e comumente utilizada em infraestruturas de próteses fixas, em casos em que não há necessidades estéticas ${ }^{22}$. Após a soldagem, a solidificação da liga Co-Cr fundida pode ocorrer mais rapidamente em comparação com as ligas de titânio, porque o calor gerado pelo laser difunde rapidamente no metal sólido envolvente. Essa rápida solidificação causa uma constrição drástica da região soldada, ocorrendo uma concentração de tensão e criam-se fissuras. Essas fissuras podem ser os pontos de partida para a fissura de corrosão por tensão (SCC) ou fadiga e podem afetar não apenas a resistência à tração, mas também o comportamento de SCC e fadiga. O SCC e o comportamento à fadiga são fatores importantes porque influenciam a vida útil das próteses soldadas a laser ${ }^{4}$.

Pode-se considerar que a espessura do material a ser soldado é um fator crítico para a obtenção de uma solda adequada. Neste trabalho, como forma de padronização da área de soldagem, foram utilizadas barras com $2 \mathrm{~mm}$ e meio de diâmetro. As ligas de ouro produzem próteses com qualidade e facilidade de solda ${ }^{17,18}$. Entretanto, a introdução de materiais mais econômicos e com propriedades compatíveis implicou em um decréscimo do uso do ouro, particularmente em próteses extensas, tanto pelo custo quanto pelas limitações mecânicas desse material. Yoshinari et al. ${ }^{23}$ (2016) avaliaram a resistência à tração entre as ligas de CoCr e o cilindro de ouro unido com soldas de ouro de alta fusão. Também avaliaram a resistência à corrosão da estrutura de $\mathrm{CoCr}$ e cilindro de ouro em comparação com a liga de ouro unida ao cilindro de ouro. A resistência de união das amostras de cilindros de $\mathrm{CoCr} / \mathrm{Solda} / O$ Oro apresentou valores semelhantes aos dos espécimes de liga de Ouro/Ouro.

É importante considerar a experiência do operador para conseguir juntas de solda de características semelhantes ${ }^{18}$. A técnica convencional de soldagem utiliza chama direta através do maçarico de gás/oxigênio e necessita da aplicação do fluxo para minimizar a oxidação do metal, porém estes dois fatores podem oca-
MENEZES VP

DIAS SC

CARVALHO GAP

RAMOS EV

FRANCO ABG

KREVES

AVALIAÇÃO DA RESISTENCIA FLEXURAL EM DIFERENTES MÉTODOS DE SOLDAGEM

\section{5}

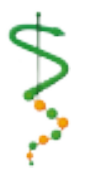

REV, ODONTOL.

UNIV, CID, SÃo PAULO

2017; $29(3)$ : 215-29, SET-DEZ 
MENEZES VP

DIAS SC

CARVALHO GAP

RAMOS EV

FRANCO ABG :

KREVE $S$

AVALIAÇÃO DA RES ISTENNCIA

FLEXURAL EM DIFERENTES MÉTODOS DE SOLDAGEM

226

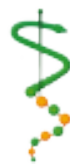

REV, ODONTOL.

UNIV, C I D. SÃO

PAULO

2017; 29(3):

215-29, SET - DEZ
I SSN 1983-5183

sionar defeitos de vários tipos nas juntas soldadas como, por exemplo, a inclusão de gases ou a inclusão do próprio fluxo, principalmente em juntas com grande espessura, devido à incapacidade de dissolução desse fluxo pela chama ${ }^{14}$. A soldagem do forno (soldagem pós-cerâmica) é a melhor escolha quando a aplicação de porcelana já foi realizada. A temperatura máxima pode ser controlada para permitir o fluxo de solda sem distorcer a porcelana $^{18}$. Uma abordagem alternativa para a soldadura convencional de tocha ou forno é a utilização de uma fonte de calor infravermelho ${ }^{18}$.

NaBadalung e Nicholls ${ }^{13}$ (1998) relataram que as cargas de fratura para as juntas soldadas a laser foram menores do que nas amostras fundidas. A falha ocorreu imediatamente adjacente aos cordões de solda, o que sugeriu alterações microestruturais. Os resultados encontrados por NaBadalung e Nicholls ${ }^{13}$ (1998) indicaram que a soldadura a laser $\mathrm{Nd}$ :YAG influenciou as propriedades da liga Co-Cr. Os dados mostraram que as cargas de fratura para as juntas soldadas a laser foram menores do que as amostras fundidas, e a falha ocorreu imediatamente adjacente à solda. Isso sugeriu que houvesse alterações microestruturais na HAZ da liga Co$-\mathrm{Cr}$.

No presente estudo, a liga escolhida foi a de Co-Cr, considerando seu emprego justificado por custo reduzido e adequado comportamento mecânico para as necessidades odontológicas. Em seus estudos laboratoriais vários autores ${ }^{4,24,25}$ relataram que o custo da infraestrutura metálica pode ser reduzido utilizando-se ligas não nobres. Estudos como o de Souza et al. ${ }^{26}$ (2000) e Baba et al. ${ }^{4}$ (2004) também demonstraram que características aceitáveis de adaptação e capacidade de soldagem podem ser obtidas utilizando o Laser nesse tipo de liga.

Um dos testes mais utilizados para checar a qualidade das soldas tem sido o teste de resistência flexural sob cargas compressivas aplicadas em pontos específicos da estrutura protética. Segundo Anusavice et al..$^{14}$ (1985), Rocha et al. ${ }^{12}$ (2006) e Silva et al. ${ }^{10}$ (2008) esse teste simula, de forma satisfatória, a condição clínica das próte- ses sob cargas compressivas provenientes da mastigação. Tomando-o como base, o presente estudo utilizou o referido teste, empregando infraestruturas construídas a partir da liga de Co-Cr.

No presente estudo, avaliou-se a influência de três métodos de soldagem: brasagem (chama direta), solda a laser e soldagem elétrica, sobre a resistência flexural de infraestruturas protéticas de Co-Cr. O método de soldagem influenciou significativamente a resistência flexural das infraestruturas protéticas, o que está em concordância com outros estudos que utilizaram o mesmo teste de resistência flexural ${ }^{27,28}$.

Para confecção do modelo-mestre, foram posicionados dois implantes à distância de $21 \mathrm{~mm}$. Essa medida permitiu que o efeito de distorção gerado, realizando apenas um ponto de solda, pudesse ser melhor avaliado, evitando-se, assim, a incorporação de mais variáveis ao trabalho como, por exemplo, a soldagem de uma PPF de vários segmentos subsequentes. Além disso, permitiu verificar a viabilidade e as possíveis vantagens em se utilizar a soldagem a Laser em comparação com a utilização da soldagem convencional, mesmo em infraestruturas de menor complexidade, equiparando-se, assim, com outros autores ${ }^{2,20,26}$.

Existe uma grande tendência de pesquisas em relação ao titânio, devido às suas excelentes qualidades mecânicas e biológicas. ${ }^{6,11,16}$. Entretanto, foi verificado que essa liga também apresenta algumas dificuldades em relação à aplicação de cerâmica, por sua alta taxa de oxidação, a qual limita fortemente o uso de vários sistemas cerâmicos. Dessa forma, optamos por estudar a resistência das ligas de Co-Cr em virtude da sua facilidade de utilização.

Segundo Baba et al. ${ }^{4}$ (2004), a força de fratura necessária para quebrar as restaurações soldadas a laser é influenciada pelo metal utilizado e pelas condições de operação do dispositivo de solda a laser. Quando a solda a laser é aplicada em próteses extensas, espera-se uma baixa resistência de união, devido à pequena área de ligação, maior porosidade e pequenos espaços vazios causados pela geração de 
gás durante a queima subsequente da porcelana ${ }^{29}$.

Segundo um estudo realizado por Takayama et al. ${ }^{30}$ (2012), a influência da irradiação laser sobre o titânio pode ser considerada maior do que sobre a liga Co-Cr. Por conseguinte, observa-se que a influência da irradiação laser está concentrada no metal próximo à penetração da solda na liga de $\mathrm{Co}-\mathrm{Cr}$, enquanto que no titânio a influência ocorre em todo o metal.

Os resultados obtidos durante a realização do presente trabalho mostram ter havido diferença apenas no grupo de solda a laser, ficando o grupo de solda convencional e solda mista com o maior valor de média de resistência à flexão. Os resultados deste estudo demonstram que, utilizando a soldagem por fusão a laser para unir as duas superfícies de Co-Cr, a resistência à tração foi maior do que utilizando a brasagem elétrica. Isso pode ser explicado pelas características de cada técnica de união. Para uma junta formada pela soldadura elétrica, a ponta do eletrodo gera aproximadamente $1300 \mathrm{C}$, o que está abaixo do ponto de fusão (1370 C) do metal original. Essa temperatura é necessária para permitir que o enchimento se molhe e se ligue à superfície do metal original. Assim, não há fusão do metal original ${ }^{13}$. A maior resistência flexural das infraestruturas de $\mathrm{Co}-\mathrm{Cr}$ soldadas pelo método chama direta observada no presente estudo está em concordância com resultados de outros autores ${ }^{11,12}$.

Os grupos de solda convencional e solda mista produziram corpos de prova com valores de resistência superiores. O que se observa na prática e o que se compara na literatura é a dificuldade em se conseguir um padrão de qualidade para todas as peças soldadas. Os melhores valores foram encontrados nos grupos chama direta e mista, e isso pode ser explicado pelo critério de qualidade na confecção dos espécimes.

Chaves et al..$^{18}$ (1998) encontraram que maioria das juntas de solda fraturaram de modo coeso através da solda, mas alguns espécimes apresentaram falha no metal original. Essa técnica de solda exige um controle meticuloso do ponto focal porque, se isso não for alcançado, a solda irá derreter desigualmente e resultar em juntas mais fracas. Uma atenção cuidadosa às flutuações de tensões é necessária quando se utiliza a unidade infravermelha, porque tais alterações podem mudar a eficiência do processo de soldagem. As amostras soldadas com a técnica de infravermelho foram as mais fracas para cada liga.

\section{CONCLUSÃO}

De acordo com a metodologia aplicada no presente estudo, pode-se concluir que:

a) Os métodos de soldagem convencional e mista apresentaram valores semeIhantes ao de resistência flexural;

b) O procedimento de soldagem a laser de estruturas implanto-retidas fabricadas em liga de Co-Cr mostrou resistência diminuída comparada à soldagem convencional e à mista;

c) A pré-fixação com eletro-solda não diminui a resistência da soldagem mista.
MENEZES VP

DIAS SC

CARVALHO GAP

RAMOS EV

FRANCO ABG

KREVES

AVALIAÇÃO DA

RESISTENNCIA

FLEXURAL EM

DIFERENTES

MÉTODOS DE

SOLDAGEM

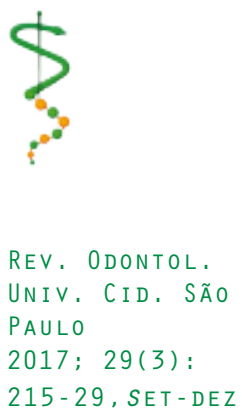


MENEZES VP

DIAS SC

CARVALHO GAP

RAMOS EV

FRANCO ABG

KREVE $S$

AVALIAÇÃO DA

RES ISTENNCIA

FLEXURAL EM

DIFERENTES

MÉTODOS DE

SOLDAGEM

228

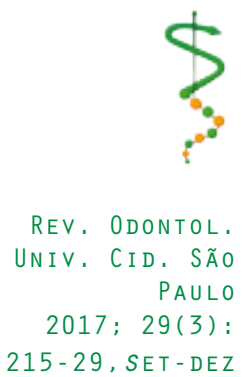

\section{REFERÊNCIAS}

1. De Castro GC, De Araujo CA, Mesquita MF, Consani RL, Nobilo MA. Stress distribution in $\mathrm{Co}-\mathrm{Cr}$ implant frameworks after laser or TIG welding. Brazilian dental journal 2013 24(2):147-51.

2. Madhan Kumar S, Sethumadhava JR, Anand Kumar V, Manita G. Effects of conventional welding and laser welding on the tensile strength, ultimate tensile strength and surface characteristics of two cobalt-chromium alloys: a comparative study. Journal of Indian Prosthodontic Society 2012 Jun;12(2):87-93.

3. Rubo JH, Souza EA. Finite element analysis of stress in bone adjacent to dental implants. The Journal of oral implantology 2008 34(5):248-55.

4. Baba N, Watanabe I, Liu J, Atsuta M. Mechanical strength of laser-welded cobalt-chromium alloy. Journal of biomedical materials research Part B, Applied biomaterials 2004 May 15;69(2):121-4.

5. Schiffleger BE, Ziebert GJ, Dhuru VB, Brantley WA, Sigaroudi K. Comparison of accuracy of multiunit one-piece castings. The Journal of prosthetic dentistry 1985 Dec;54(6):770-6.

6. Torsello F, Di Torresanto VM, Ercoli C, Cordaro L. Evaluation of the marginal precision of one-piece complete arch titanium frameworks fabricated using five different methods for implant-supported restorations. Clinical oral implants research 2008 Aug;19(8):772-9.

7. Atoui JA, Felipucci DN, Pagnano VO, Orsi IA, Nobilo MA, Bezzon OL. Tensile and flexural strength of commercially pure titanium submitted to laser and tungsten inert gas welds. Brazilian dental journal 2013 Nov-Dec;24(6):630-4.
8. Orsi IA, Raimundo LB, Bezzon OL, Nobilo MA, Kuri SE, Rovere CA, et al. Evaluation of anodic behavior of commercially pure titanium in tungsten inert gas and laser welds. Journal of prosthodontics : official journal of the American College of Prosthodontists 2011 Dec;20(8):628-31.

9. Chai T, Chou CK. Mechanical properties of laser-welded cast titanium joints under different conditions. The Journal of prosthetic dentistry 1998 Apr;79(4):477-83.

10. Silva TB, De Arruda Nobilo MA, Pessanha Henriques GE, Mesquita MF, Guimaraes MB. Influence of laser-welding and electroerosion on passive fit of implant-supported prosthesis. Stomatologija 2008 10(3):96-100.

11. Hart CN, Wilson PR. Evaluation of welded titanium joints used with cantilevered implant-supported prostheses. The Journal of prosthetic dentistry 2006 Jul;96(1):25-32.

12. Rocha R, Pinheiro ALB, Villaverde AB. Flexural strength of pure $\mathrm{Ti}, \mathrm{Ni}-\mathrm{Cr}$ and $\mathrm{Co}-\mathrm{Cr}$ alloys submitted to $\mathrm{Nd}$ :YAG laser or TIG welding. Brazilian dental journal 2006 17(1):20-3.

13. NaBadalung DP, Nicholls JI. Laser welding of a cobalt-chromium removable partial denture alloy. The Journal of prosthetic dentistry 1998 Mar;79(3):285-90.

14. Anusavice KJ, Okabe T, Galloway SE, Hoyt DJ, Morse PK. Flexure test evaluation of presoldered base metal alloys. The Journal of prosthetic dentistry 1985 Oct;54(4):507-17.

15. Yannikakis S, Prombonas A. Improving the fit of implant prosthetics: an in vitro study. The International journal of oral \& maxillofacial implants 2013 Jan-Feb;28(1):126-34.

16. Willis LM, Nicholls Jl. Distortion in dental soldering as affected by gap distance. The Journal of prosthetic dentistry 1980 Mar;43(3):272-8. 
17. Wiskott HW, Macheret F, Bussy F, Belser UC. Mechanical and elemental characterization of solder joints and welds using a gold-palladium alloy. The Journal of prosthetic dentistry 1997 Jun;77(6):607-16.

18. Chaves M, Vermilyea SG, Papazoglou E, Brantley WA. Effects of three soldering techniques on the strength of high-palladium alloy solder joints. The Journal of prosthetic dentistry 1998 Jun;79(6):677-84.

19. Angelini E, Pezzoli M, Rosalbino F, Zucchi F. Influence of corrosion on brazed joints' strength. Journal of dentistry 1991 Feb;19(1):56-61.

20. S. Huling J, Ernest Clark R. Comparative distortion in three-unit fixed prostheses joined by laser welding, conventional soldering, or casting in one piece. J Dent Res 1977 56(2):128-34.

21. Jemt T, Lekholm U. Measurements of bone and frame-work deformations induced by misfit of implant superstructures. A pilot study in rabbits. Clinical oral implants research 1998 Aug;9(4):272-80.

22. Hulterström M, Nilsson U. Cobalt-chromium as a framework material in implant-supported fixed prostheses: A 3-year follow-up. The International journal of oral \& maxillofacial implants 1991 9(1):449-54.

23. Yoshinari M, Uzawa S, Komiyama Y. Hybrid framework with cobalt-chromium alloy and gold cylinder for implant superstructure: Bond strength and corrosion resistance. Journal of prosthodontic research 2016 Oct;60(4):274-81.

24. Blustein R, Depaul BM, Barnhart RC, Green KA. A reliable technique of post soldering of nonprecious ceramic units. The Journal of prosthetic dentistry 1976 July;36(1):112-14.
25. Srimaneepong V, Yoneyama T, Kobayashi E, Doi H, Hanawa T. Comparative study on torsional strength, ductility and fracture characteristics of laser-welded alpha+beta Ti-6Al-7Nb alloy, CP Titanium and $\mathrm{Co}-\mathrm{Cr}$ alloy dental castings. Dental materials : official publication of the Academy of Dental Materials 2008 Jun;24(6):83945.

26. Souza PCRD, Dinato JC, Bottino MA, Guastaldi AC. Brazing and laser welding of a Ni-Cr alloy. Braz Dent Sci 2000 3(2):7-16.

27. Jemt T, Henry P, Linden B, Naert I, Weber $\mathrm{H}$, Bergstrom $\mathrm{C}$. A comparison of laser-welded titanium and conventional cast frameworks supported by implants in the partially edentulous jaw: a 3-year prospective multicenter study. The International journal of prosthodontics 2000 Jul-Aug;13(4):282-8.

28. Lyra E Silva JP, Fernandes Neto AJ, Raposo $\mathrm{LH}$, Novais VR, De Araujo CA, Cavalcante $L A$, et al. Effect of plasma welding parameters on the flexural strength of Ti-6Al-4V alloy. Brazilian dental journal 2012 23(6):686-91.

29. Zupancic R, Legat A, Funduk N. Tensile strength and corrosion resistance of brazed and laser-welded cobalt-chromium alloy joints. The Journal of prosthetic dentistry 2006 Oct;96(4):27382.

30. Takayama Y, Nomoto R, Nakajima H, Ohkubo C. Effects of argon gas flow rate on laser-welding. Dental materials journal 2012 31(2):316-26.

Recebido em 06/03/2017

Aceito em 14/08/2017
MENEZES VP

DIAS SC

CARVALHO GAP

RAMOS EV

FRANCO ABG

KREVES

AVALIAÇÃO DA RES ISTENNCIA FLEXURAL EM DIFERENTES

MÉTODOS DE

SOLDAGEM

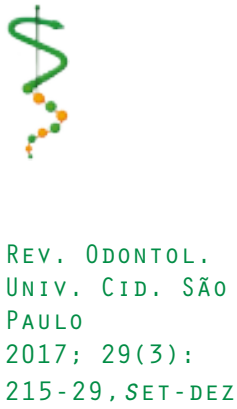

